\title{
A Predictive Geological Tool of Type 3 Diabetes (Alzheimer's Disease): The Polygonal Vortex Mineralisation Model a Medical Geology Perspective
}

Journal of Diabetes and Endocrinology Research

Research Article

Hochwimmer B ${ }^{1}$, Ziarati $\mathrm{P}^{2}$, Selinus $\mathrm{O}^{3}$, Elwej $\mathrm{A}^{4}$, Cruz-Rodriguez LD ${ }^{5}$, Lambert Brown $\mathrm{D}^{6}$, Zayas Tamayo AM7, Moradi $\mathbf{M}^{8}$ and Cruz-Rodriguez $\mathbf{L}^{9,10,11^{*}}$

${ }^{I}$ CEO, Hochwimmer B. \& Asso. Pty Ltd, Albury, NSW, Australia ${ }^{2}$ Nutrition and Food Sciences Research Center, Tehran Medical

Sciences, Islamic Azad University, Tehran, Iran

${ }^{3}$ Linneaus University, Linnegatan 2, Kalmar 39233, Sweden

${ }^{4}$ Laboratory of Animal Physiology, science faculty of Sfax, University of Sfax, Tunisia

${ }_{5}^{5}$ ELIDAN genome SAS, 1 avenue du Lycée, 77130 Montereau Fault Yonne; France.

${ }^{6}$ CEO, Family Physician, FCMC \& ExCELab Co. Ltd, Jamaica

${ }^{7}$ ExCELab Co. Ltd., Microbiologist of Environmental Biotechnology

Department, Jamaica

${ }^{8}$ Department of Cell \& Molecular Biology, Faculty of Biological

Sciences, Kharazmi University, Tehran, Iran

${ }^{9}$ ExCELab Co. Ltd., Manager Director of Environmental

Biotechnology Department., Jamaica

${ }^{10}$ CEO, ELIDAN Dynamic LLC, 1602 Windermere Way, Tampa,

$F L, 33619$, USA

${ }^{11 *}$ CEO, ELIDAN genome SAS, 1 avenue du Lycée, 77130 Montereau

Fault Yonne; France.

Emails:ceo@elidan-genome.com ;

luis.cruzrguez@gmail.com

"Correspondence author

Dr. CRUZ-RODRIGUEZ Luis

CEO,

ELIDAN genome SAS,

1 av du Lycée,

77130 Montereau FY; France

Submitted : 01 April 2020 ; Published : 10 April 2020

Essential selenium and zinc deficiencies biochemistry and physiology is reviewed to impact neurobiology and Alzheimer's significantly whilst metal pollutants impact early Alzheimer's progression. A predictive bio-geospatial tool for such impacts considers Taranjebin-Mannagum selenium, by way of the Polygonal Vortex Mineralization Model (PVM) in the central Asian Metallogene. Manna becomes Taranjebin on selenium hyper-accumulation, then highly valued ethnomedically for immune disorders, hyperbilirubinemia, also mitigating diabetes, including Alzheimer's risk, combating low birth weight known to influence diabetes. Diabetes mitigation source regions of hyper accumulating organic selenium are described within deficient desert terrains. PVM was initially developed as a predictive mineral exploration tool. It is proposed for the first time a novel use as a geological framework of potential public health risks including diabetes. PVM is now intended to cover all forms of mineralization and anthropogenic by products. Similarly, to mineral exploration targeting, PVM can help 'prospect' for health risks. That's helpful, as most communities never undergo geogenic epidemiological studies. PVM defines mineralization fluid pathways, often in polygonal fracture sets, from microscopic to macro fractal niche scaled, as previously reported, providing high fracture surface activity. Essential minerals and or pollutants are then geologically remobilization to biota, impacting health through food bowl, water and air quality. Significantly, PVM-geogenic models may provide mappable 'Medical Geology indicators' of essential elements or pollution when qualified biogeochemically, as "Geogenic Public Health Indices" (PVM-HI). Ideally, they and other indices help produce "The Medical Geology Map of The Globe", supporting public health in developing countries and where epidemiological and Metallogene supervision of it is sparse. One should add warfare and industrial metalliferous debris 'indices'. The author's expectation is this paper will engender PVM-HI debate on such "prospecting" utilities for unrecognized Alzheimer's, other health risks, and help unravel their core pathways through bio-geospatial analysis. Taranjebin selenium biogeochemical-ethnomedical qualified data varying with geology provide PVM-HI examples. Selenium-bio-fertility is herein linked to plate subduction beneath former Iran-Pakistan-Afghanistan micro plate collision boundaries. Interestingly, present country borders conform to former micro plate boundaries, though cultural aspects follow geological features. This has physiographic-geogenic mobility implications for selenium and community Medical Geology. Selenium, sourced primarily from evolving calc-alkaline to alkalic Cenozoic magmatism and fault fracture networks (PVM), confers Taranjebin ethnomedical quality, transitioning higher towards back arc environments respectively. The Cimmerian orogenesis responsible effected the Eurasian plate 
between Turkey and Thailand since the Mesozoic, widening PVM-HI Medical Geology 'prospecting'scope. Gondwana micro continent collation included the Central East Iran Microplate (CEIM), where the Fabaceae manna gum hosts, and Alhagi maurorum was studied. Taranjebin selenoglycoproteins are considered the active selenium species utilized by primal desert communities. Taranjebin with other manna gums are still widely traded, as they were in antiquity. With demographic changes underway it is essential primal confounding physicochemical environment factors and metal speciation impacting Alzheimer's are studied soon, with epidemiology, genetics and anthropology. Mediterranean to Central Asia manna selenium studies are recommended before modern life completely overshadow primal geogenic factors in diabetes. This Medical Geology perspective will help unravel some confounding factors in type 3 diabetes (Alzheimer's disease).

Keywords: Polygonal Vortex Mineralization Model (PVM), Alzheimer's Disease, Type 3 Diabetes, PARP-1, Medical Geology, Uranium, Selenium, Zinc, Mitochondrial Genome, DNA Damage, Pollution, DNA Repair

\section{Introduction}

Parched central Asian lands, have 'islands' of fertility conferred by founding geology in which peoples since antiquity managed to locate concentrated sources of essential selenium and zinc to mitigate health issues of deprivation. They include those more commonly thought to afflict modern societies, diabetes, including Alzheimer's one can consider in ways 'Type-3' diabetes. Biochemical and biological activity of essential selenium and zinc in disease mitigation is reviewed for diabetes along with pollution potentially contributing to neurological disorders such as Alzheimer's and Parkinson's disease.

A selenium source in parched Central Asia is Taranjebin manna gum. This gum is an exudate from the Fabaceae Alhagi genus, commonly called Camelthorns or Manna tree of which few species exist. They are very deeply rooted; even small bushes may have roots exceeding $15 \mathrm{~m}$ depth. Geogenically selenium species reduction by bacteria at depth is inaccessible to biota. Soil analyses (Ziarati P. and Hochwimmer B.; 2018) demonstrated friable porous sandy soils. Un-flooded, yet moist at depth, they trend oxygenated, generally alkaline aiding geogenic selenium mobility. Manna gum formation is stimulated by insect scaring of Alhagi species which appears to be selective. Larva of the Lepidoptera Coleophora argyrella feeds exclusively on Alhagi maurorum for example. Taranjebin gum becomes tear shaped and golden in color on selenium maturation loading, distinguishing field quality and market value, thereby presumably ethnomedical efficacy (Ziarati P. and Hochwimmer B.; 2018).

One speculates if insects, humans and other sugar-nectar feeders generally are in symbiotic relations with the Camelthorns as this genus appears to convert hyper accumulated toxic inorganic selenium into 'palatable' selenoglycoproteins within broader regions of deprivation. Fabaceae evolution towards selenium hyper accumulation may have begun around $11 \mathrm{Ma}$ in these regions (Ziarati P. and Hochwimmer B.; 2018).

Worldwide, Fabaceae species are known selenium hyper accumulators in regional Metallogene. Notably in the mineral districts of Cripple Creek, Colorado, Fabaceae species were very successfully utilized historically in botanical prospecting for mineral deposits. The concept in this paper is that such rational can be used in 'reverse', to 'prospect', through PVM analysis, geogenic driven health issues; the mitigation and deprivation of essential selenium and zinc in primal cultures more closely bound to land than in modern cultures.

Taranjebin ethno medicine-nutrient has been used for millennia, primarily for treatment and prevention of immune disorders, hyperbilirubinemia in new born and demonstrated effective in diabetes within Iran (Hamedi A. and col; 2015, Ziarati P. and Hochwimmer B.; 2018). Taranjebin is still traded far and wide today, as it was in antiquity. Quality varies spatially which needs to be reconciled geogenically, work that currently continues with another species, willow tree manna (Ziarati P, Hochwimmer B., personal communication, 2018). Ethnomedical efficacy for diabetes, including Alzheimer's, is manifestly thought very high selenium content from which the active components are thought to be selenoglycoproteins (Table 1, Ziarati P. and Hochwimmer B.; 2018). In deprived desert communities, Taranjebin selenium combats diabetes as an essential element and indirectly by combating low birth weight, shown to influence diabetes significantly in later life (Unjali P. and col.; 2013).

This study firstly combines 2018 Taranjebin biogeochemical analyses (Ziarati P. and Hochwimmer B.; 2018) in metallogenic context of the central Asia Cimmerian orogenesis within the Central East Iranian Micro continental plate (CEIM). Secondly, we report Taranjebin markets in light of PVM fracture analysis with magnetic, geological and terrain data and discuss potential geogenic selenium remobilization capability to manna biota, (Figures 1 and 2). Finally, we consider how geogenic selenium and zinc studies in geospatial context of combined pollution and amelioration metalloids in different ratio may help resolve some confounding factors in Alzheimer's and also benefit treatment (See Methods).

One concludes, similarly to mineral exploration for which PVM was developed, such exploration models have utility to "prospect" for health risks and amelioration factors for diabetes including Alzheimer's, a Medical Geology objective. 
PVM analysis in this way can predict depletion zones, geogenic fertile zones of various manna and selenium hyper accumulation biota within the Cimmerian orogenic zones and similarly for orogenic zones worldwide. The idea would be to test such "health exploration targets", as hypotheses, ranked as would mineral exploration targets for follow up. The discussion list some of the PVM targets of this analysis. In reality, for mineral exploration, initial PVM targeting would comprehensively involve additional geological tools and spatual gridded geochemistry, followed by drilling confirmation through mineralogy-geochemical pathway analysis to arrive at a diagnosis of genetic mineral deposit type. By analogy, Medical Geology, geospatial gridded biogeochemistry steps are carried further, 'drilling equivalent' may comprise community epidemiology, toxicology to assist diagnoses.

The main difference to mineral exploration is that such PVM targets require qualified for biological activity to consider them "Geogenic Public Health Indices" (PVM-HI). Sufficiently qualified, such PVM-HI studies could assist production of a global Medical Geology map, a multidisciplinary and multicultural enterprise. This might also assist mining projects pass a social licenced to operate, such knowledge integrated in progressive remediation. Despite good mine remediation capability, in reality this knowledge is poorly researched and integrated, knowledge of which would lead to more robust measures, particularly in developing countries. Unremediated legacy mines, some 10,000 worldwide, should be a large integral of PVM-HI analyses. A global database of combined natural and mined PVM-HI mineralisation analyses would be helpful.

There are many genetic styles of natural mineral deposit formations yielding essential elements or pollution. Geogenic mobilization paths of these elements to biota impacting human health are various and difficult to quantify in PVM-HI terms other than descriptively. Such qualification might include biota ingress analyses, health parameters, human bioassays and toxicology matched with geogenic mobility analysis of metalloids and collective impact. So far in our desert selenium PVM-HI studies we only qualify ethnomedical efficiency judged by selenium biogeochemical analyses. Nevertheless, ethnically in markets and harvest this manifest physically Taranjebin shape, being more tear dropped, together with its golden color on higher selenium content (Picture 1). We therefore consider the 14 Taranjebin samples (Table 1) so selected prior to geogenic and geological PVM-HI and biogeochemical analyses "qualified" and fit for purpose. In this study bioactivity of Taranjebin selenium in ethnomedical sense fills this nutrients health index role for PVM-HI analysis. Desirable human bioassays will improve this. Yet to be performed and compared with geospatial controls, this comprises the next steps in the diabetes Medical Geology study.

PVM was initially developed by the lead author for giant porphyry-scarn-epithermal and allied base metal associated precious metal deposit (BMAu) exploration within magmatic cordillera and island arcs globally. These metal deposits feature intensive fracturing in forearc and backarc environments, BMAu more commonly in backarc's. Due to this high fracture surface activity and its potential of geogenic remobilization to biota proposed PVM use in health prospecting within remote Metallogene. That review provides more PVM analysis detail, particularly for its fractal 'replicative' nature (Hochwimmer B. and Cruz-Rodriguez L.; 2005).

PVM concerns therefore not only genetic metallogeny and geological evolution of mineralization but importantly fracturing and its potential surface activity for geogenic element ingress to environment and biota from all genetic styles of mineralization rather than just porphyries, epithermal and BMAu mineral deposits. PVM for Medical Geology is intended to include all significant genetic styles of mineralization's and their anthropogenic byproducts of which many impact health. They include agriculture, industry and warfare debris that may be considered PVM-HI in terms of their distributive health impacts in time and space.

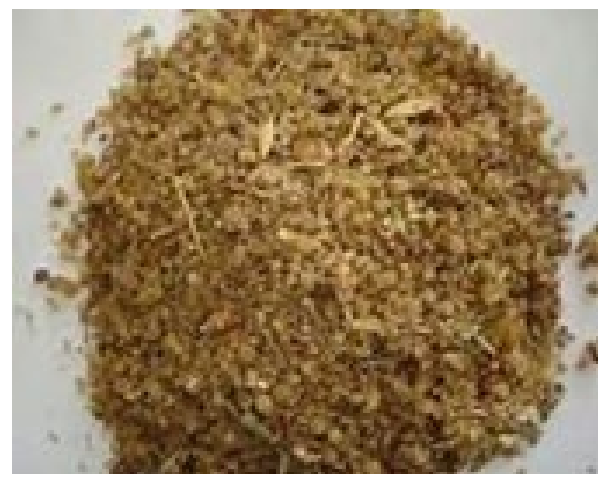

Picture 1: Taranjebin showing some tear drop and gold colors indicative of quality we demonstrate associated with hyperaccumulated selenium.

Notably, for the present study, PVM includes supergiant clustered strata bound zinc-lead-silver-barium deposits in sedimentary basins than commonly contain traces to minor selenium, as well abundant zinc (Picture 2a). Two of the largest are the Century zinc-lead-silver deposit in Queensland (traditionally $15-20 \%$ of the word production) in the Mt Isa-McArthur succession in part of the Northern Australian Platform cover and equally large Mehdi Abad zinc-silverlead-barium mine in the CEIM moving into production. Mehdi Abad lies within the markets sources of Yazd Taranjebin harvests (Table 1). The Macarthur Basin hosting Centaury has numerous other clustered mineralization's and mined or not they have potentially aeolian and ground water issues for the aboriginal communities, particular for lead, requiring special attention in remediation. So far, no Medical Geology studies have been carried out for geogenic impacted Alzheimer's here, a desirable outcome.

Barium is a very common widespread metal around such mineralization's. Barium as a chloride alone has been shown to be highly inflammatory to kidney redox states and to liver, disturbing lipid metabolism in rats. That it causes diabetes 
by itself has not been proven, though a strong contributing pollutant suspect, proven through gene expression of interleukin 1beta, interleukin 6 and TNF alpha (Eiwej A., and col., 2016, 2017). It should be noted zinc and selenium can modulate this cellular injure, also in the cerebellum shown in rat and offspring experiments (Eiwej A., and col., 2018).

Whilst mineralization's can simultaneously supply pollutants and nutrients, geogenic remobilization can separate such elements, somewhat analogous to in a chromatography column. This occurs, in both hot primary hypogene mineralizing metal transport and digenetic geogenic remobilization processes. In weathering remobilization for example, lead disseminates proximally, zinc, selenium barium distally. In hydrothermal deposits however both proximal and distal arsenic lead, antimony and barium (which can reach large lath sizes) occur, cooler hydrothermal fluids transporting these metals to distal ring fractures. In the case of barium within hot porphyries such as in molybdenite-copper deposits this may leave a central barium depletion, concentrating barium in distal ring fractures that can be kilometers apart, along with tellurium, bismuth, selenium.

Shallow gently sloping sand covers with deeper ground waters draining Mehdi Abad to agricultural valleys growing pistachio utilizing ground waters, is a test case in mind (Pictures $2 a$ and $\boldsymbol{b}$ ). Aeolian distribution of waste, ore and tailing of such systems pose health risks if not planned carefully to prevent wind dispersion and oxidizing heavy metal mobility via acid mine drainage (AMD). Natural erosive oxidative settings, also yield acid rock drainage (ARD) to ground waters that may dissolve and disperse pollutants.

Essential selenium and zinc generally follow other Sulfide mineralization's, selenium, along with tellurium having similar properties to Sulfur. Sulfide deposits of all kinds are potentially harmful such as gold quartz stockwork's that commonly contain arsenic. Yet grade dependent, they can be 'inexplicably' stimulating for growth, albeit detrimental for humans and stock long term. To cattle glaziers for example, such "Mineral Country" mark productive grounds. Cattle 'do well' on them (Phillip Lavis, personal communication, Jindera, NSW Australia, 2017).

Invariably the detrimental side of such 'productive' ground in otherwise bland nutrient devoid siliceous country rock regions is unrealized, un-quantified, a Medical Geology concern, even for developed societies such with diverse food bowl. Consequently, the next step in this respect of qualifying manna ethnomedical use would be heavy metal determinations to outline safe sources of essential selenium and zinc in a Medical Geology GIS mapping program, conveyed to desert communities in order to harvest essential nutrients safely. Also, combined essential and deleterious metalloids, in "Mineral Country" as our grazer friend terms it, is at the heart of Medical Geology and present study direction: reconciliation of such combinatorial factors biological outcomes in Alzheimer's (see Methods).
PVM, importantly in this context, refers to widely disseminated mineralization fractures that regionally impact surface waters and air quality and biota ingress. Mines when present at all, and mostly they are not, may represent 'point' sources within PVM. Reviewing biochemistry of diabetes and neurological disorders indicates geochemical perspectives of essential element deprivation and pollution are significant factors. This confirms the need of following up geological and geogenic studies and their roles in such disease within primal societies and polluted natural, industrial and urban settings (see Review: Essential Selenium and Zinc Biochemistry in health, diabetes and dementia). PVM-HI studies are ideally supported with epidemiological studies focused on primal societies intimately bound to land and "Mineral Country" geogenic inputs. Yet such studies are hardly ever conducted. PVM-HI exploration target predictions of health concerns are relevant flag marks since most communities never undergone epidemiological studies, and few of those if any include subtle underlying geogenic factors. Alzheimer's, T1, T2 diabetes studies, focus on biological and modern western cultural factors (Unjali and col.; 2013). Such paradigm one postulates, overshadow subtle geogenic impacts that may appear in primal societies and alter the incidence and outcome of disease. One should include polluted natural or industrial-urbane environments as PVM-HI indices, particularly in children, before modern life in older age elicits confounding factors to study. Alzheimer's pathologies for example have been noted in children in such polluted environments (Calderón and col.; 2018). Diabetes related to deprivation of essential selenium and zinc are particularly important in primal cultures directly connected with variable physiography and geological foundations, as both preventative and mitigating factors to such adverse pollution. In this way Medical Geology perspectives may help unravel some confounding factors in type 3 diabetes (Alzheimer's disease).

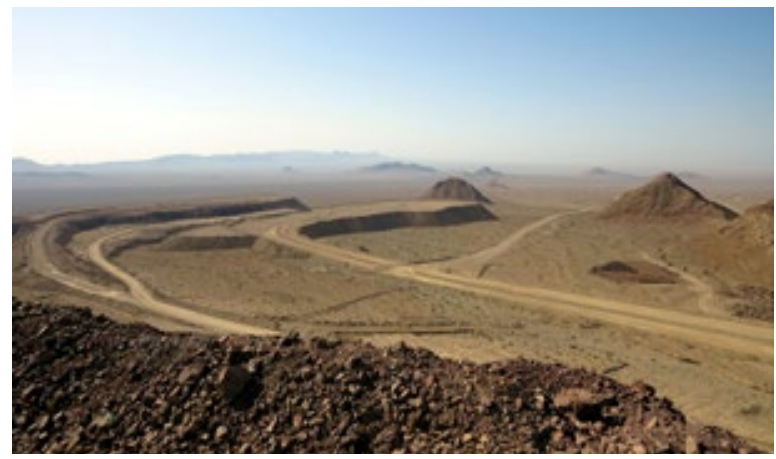

Piciture 2a

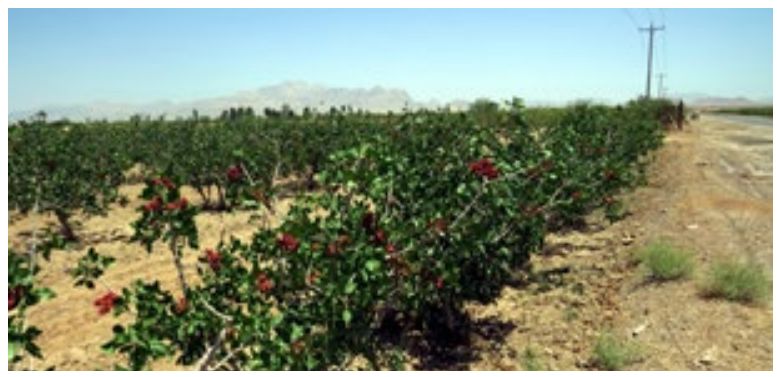

Picture 2b 
Pictures 2a and 2b: Mehdi Abad zinc-silver-lead-barium mine Yazd district showing ore, tailing \& waste stock piles. Photo 2 b: agricultural valley with pistachio down slope of the mine (just behind the right side of the central range), irrigated with ground waters. It would be helpful to separate essential elements from pollutants when in close proximity, and the natural geogenic environment can help this process, a geogenic analogy to chromatograph say, through ground waters geological profiles.

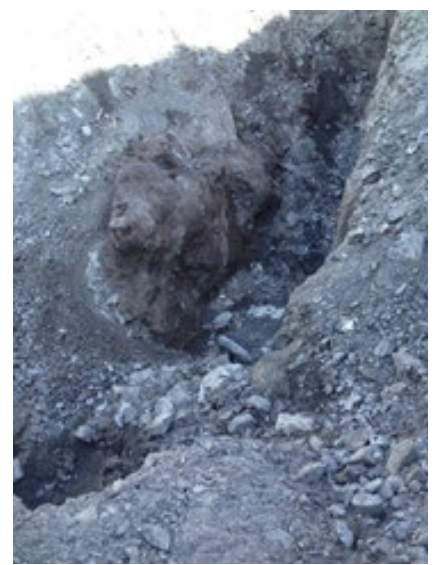

Picture 3: Replete Podiform chromite mineralization occur in the CEIM ophiolites, provide chromium and nickel, sometimes palinoids. This example near the UDMA.

\section{Conflicts of Interest}

None of the authors have any conflicts of interest associated with this study. To comment on virology (not covered in this study); material interest. A divisional group leader in research of a human vaccine against corona virus is by Dr. CRUZRODRIGUEZ L. (LAMBERT BROWN D. and col; 2020)

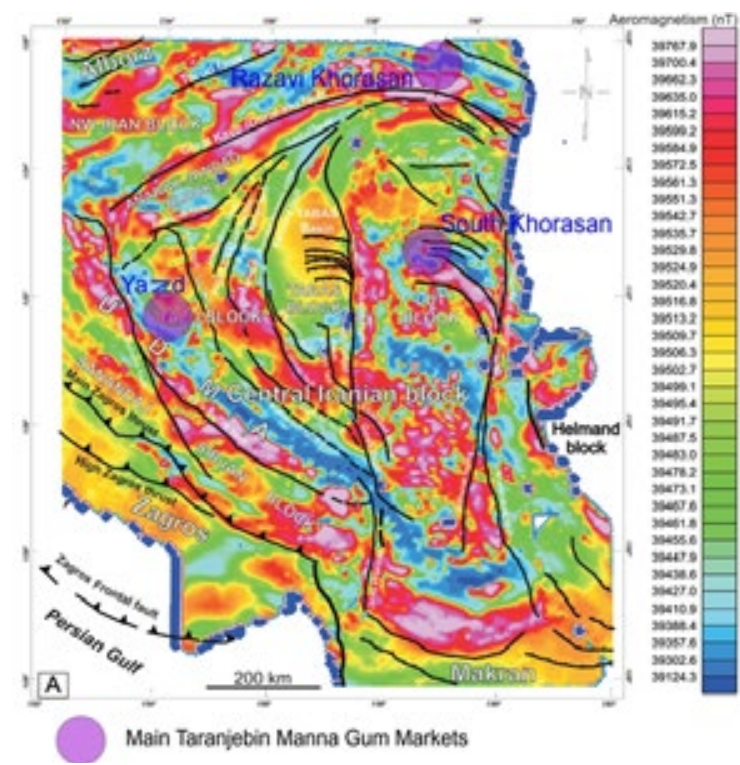

Figure 1: Gridded Aero Magnetics for east Iran showing the former Central East Iran Microplate (CEIM) and main fault structures with superimposed Taranjebin Market sources. Based on Gridded aeromagnetic survey, Geophysics Institute of the University of Tehran, Figure 16 (A) in Konon A and Col., (2016)

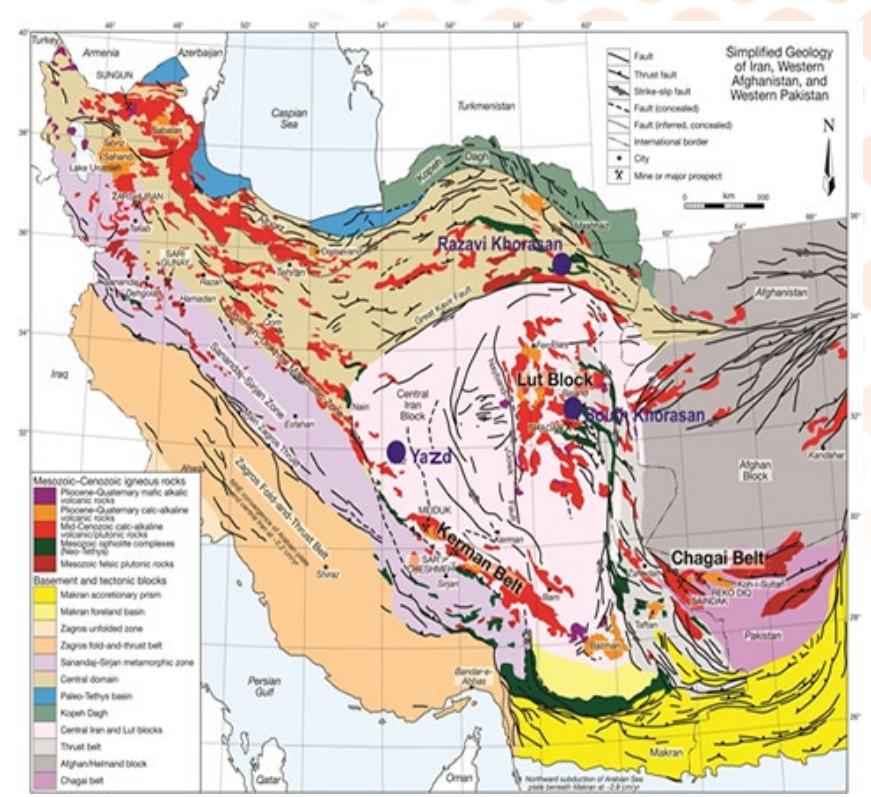

Figure 2: Distribution of Manna Sources in Iran (blue dots), superimposed on the Simplified Geology of Iran, and surround: Selenium prospective Mid Cenozoic calc-alkaline magmatic arcs are shown south of Yazd, along with Mesozoic plutonic rocks and Pliocene-Quaternary clac-alkaline in the ChagaiSouth Khorasan in the east, and similar series in the NE of Iran around Razavi-Khorasan. $\neg \neg \neg$ Adapted with permission from Ziarati P. and Hochwimmer B. (2018). Base Map modified form the Geological Survey of Iran, 1989, and unpub. Data of Berberian and King (1981), Bonini et al. (2003), Mohajjel et al. (2003), and Regard et al. (2005) as presented in Figure 1, 1,456 of Richards. JP. et al. (2006) with permission.

\section{Review}

\section{Confounding Cultural and Environmental Factors in} Diabetes

Reconciling interactions of causative environmental factors and variables including innate susceptibility leading us to risk assessments, preventative and curative efforts of diabetes at individual and population levels are confounding. Biological and geogenic environmental factors propelling diabetes, including Alzheimer's disease to alarming rates with massive projected burden worldwide are poorly understood.

Moreover, in some populous developing nations such as Iran where $75 \%$ of people are under the age of 35 adopting western dietary habits, metabolic disease is projected to escalate in massive episodic financial and suffering burden all at once. Studies in developing nations are very much needed to circumvent disease. Despite massive research efforts we are a very long way from reconciling and discovering all environmental risk factors, their confounding biological interplay including, metal (loid) amelioration, amidst ever increasing burden of Type 1 (T1D) and Type 2 (T2DM) and Alzheimer's. Perplexing studies include: sleep disruption and hours above normal escalating T2DM (Unjali and col; 2013); muscular-endocrine factors such as running $100 \mathrm{~m}$ 
verses $10 \mathrm{~km}$ equivalence reducing death by all known causes; genetics on top of cultural factors in south Asians and other cultural groups; diet, not only quantity, but quality and type. Thoughts of geogenic interaction in diabetes research are routinely ignored, a serious mistake we believe, and trust this paper helps to change this mindset. Despite knowing positive essential selenium and zinc influences on health, including diabetes, rarely are geogenic and geological environment considered in diabetes studies at primal cultural levels that can be revealing, potential helping to unravel some confounding factors in disease.

We review the biochemistry of selenium in relation to dementia including Alzheimer's, the possible role of Taranjebin selenoglycoproteins amelioration of diabetes, including previous geogenic zinc studies in surface and ground waters in relation to childhood T1D incidence in Sweden. Low Alzheimer's incidence in relation to nut consumption noted in China and elsewhere could also be connection in light of selenium and zinc levels, in addition to beneficial oils. Brazil and pistachio nuts (see Picture 2b) are mooted selenium accumulators, though levels will be geographically dependent on geology.

Research focused on such elemental primal rural and city "base line" studies globally, in different societies, would balance modern western focal studies that have in some ways skewed metabolic syndrome research. It is important, for their effects, including that imparted by primal geogenic settings, may be distorted, unrecognized, largely overshadowed by modern lifestyles of 'excess' on metabolic diseases, yet impact disease onset and nature in unknown ways. Nuance in physicochemical environmental settings we surmise are important to more clearly differentiate responses. Combined with primal studies this may aid prevention and combat diseases in different ethnic cultural settings and geological-anthropogenic environments.

For example, in Alzheimer's dementia indications of amyloidal/tau have been found in brain lesions of 203 subjects of Mexico City subjects less than 40 years old in high pollution settings suggestive of contributing. Sadly, the youngest subject was just 11 years old (Calderón-Garcidueñasa L., 2002, 2018). This study and others highlight's the potential importance of pollution in Alzheimer's. Clearly to PVM-HI analyses in Medical Geology mapping, one should add an industrial pollution index.

To this industrial anthropogenic pollution base, one must also add substantive warfare conflict debris.

Depleted uranium has been anecdotally cited by Iraqi doctors to escalate Leukemia rates 50 -fold (based on hospital admission rates) primarily in children handling these materials. Whilst this strong suspect awaits on site proof, amidst confounding war contributions of living condition to sanitation, pathogens, lack of folate etc., adding tungsten debris to the list of suspects is recommended as direct bodily contact over time is carcinogenic. How this affects diabetes in later life is unknown, though just epigenetic implications seem dire, let alone known factors of low birth weight accompanying warfare to diabetes risks.

The industrial base effects on soils and industrial technosol are often urbanized into green space and city community market gardens that must also be counted. It is estimated most soils proximal to distal around industrial centers in china used for market gardens to sustain the largest population on earth are now very heavily polluted. The effect of this toxic metal and organic milieu on top of dietary energy consumption excess affecting metabolic disease in cities globally is unknown. Additionally, provinces in China have distal to proximal food bowl and water supply impacted by highly mineralized Orogenic belts. Some have remobilized arsenical ground waters 'captured' in coal deposits to percentage arsenopyrite levels. The International Medical Geology Association (IMGA), (Selinus O. and col., 2005) have published on this subject and others have been successfully active in preventative amelioration of the devastating toxic arsenic impacts to surrounding communities, such as at Guizhou. Extremely expensive remediation and research is a top priority for Chinese soils and some of us are working on alternative less expensive solutions.

\section{Essential Selenium and Zinc Biochemistry in Health, Diabetes and Dementia}

Various forms of selenium(Se) found in food and water including selenite, selenate, selenocysteine, and selenomethionine provide selenium for the human body ( $\mathrm{Lu} \mathrm{J}$ and Holmgren A.; 2008). Selenium plays a significant role in mammalian biology in the form of selenoproteins, as the 21st amino acid (Sec). Selenocystein, a cysteine analog has the sulfur-containing side chain changed to a Se-containing side chain (Kurokawa S. and Marla J.; 2013).

Not only do the Selenoproteins enhance the immune system (Avery JC. and Hoffmann PR.; 2008), which is in line with the ethnomedical use of Taranjebin for diabetes, but also, they involve some oxidative reactions in mitochondria, and are important for brain nerve function. Therefore, decreased function of selenoproteins through either deficiency in selenium sources or reduced selenoprotein expression (Vindry C., Guillin O. and col; 2019), can lead to impaired cognitive function and neurological disorders such as Alzheimer's disease (AD) (Mecocci P. and col; 2012), Parkinson's disease (PD) impaired function of glutathione peroxidase selenoenzymes), Huntington's disease (HD, Impaired function of glutathione peroxidases), and epilepsy (Pillai R., Uyehara-Lock JH., and col; 2014).

Conceivably metal(loid) pollution may interfere with selenium and selenoprotein function, given selenium chemical similarity to sulphur and its environmental species such as arsenopyrite, whist arsenates in turn can substitute for phosphates, important in cell signaling regulation, energy and genome. Here DNA damage is pertinent, in ADP-ribose and PARP-1 over activation in neuron pathogenesis (see following). Higher selenium, also 
selenium + nickel combination (judged form nail clippings), is known to mitigate arsenic related cancer risk in mine workers for example.

A potential role in selenate mitigation of Tau pathology from selenoprotein $\mathrm{S}$ was found to reduces endoplasmic reticulum stress-induced phosphorylation of Tau (Rueli R. and col; 2017), and selenium levels to mortality in children born to HIV mothers. (Kapa R. and col; 2005). Seleno-compounds have been found to mediate an anti-cancer effect by inducing oxidative stress and DNA damage accumulation and, consequently, apoptosis (Avery JC. and Hoffmann PR.; 2008).

Essential seleno-compounds and zinc are important for DNA repair mechanisms, crucial components also for the maintenance of the essential mitochondrial genome. In this respect note the ethnomedical use of Taranjebin selenium in neonatal settings. Among them, base excision repair (BER) processes, dedicated in part to oxidative DNA damage, are individually well known in mitochondria. However, (GarreauBalandier I., and col.; 2014), demonstrated that a large range of glycosylase activities were present in Drosophila mitochondria modified during aging. DNA damage is the key activator of the enzyme poly (ADP-ribose) polymerase1 (PARP-1) who's over activation has been proven to be associated with the pathogenesis of numerous central nervous system disorders, such as ischemia, neuroinflammation, and neurodegenerative diseases (Martire S.; 2015). We conclude from PVM insight a new perspective regarding the design of possible therapeutic agents or the identification of biomarkers may emerge. To this we should add the epigenetic environment of depletion in expectant mothers, as was initially determined in closing months of WW2. This seems reminiscent of ethnomedical Taranjebin selenium use in zones of depravation of expectant moths and neonatal babies.

Selenoglycoproteins are found to attenuate adhesion of tumor which may ameliorate primary to secondary organ transmission. This involves inhibition of NF- $\mathrm{kB}$ pathways, and it was found that not only the selenium was involved but also the glycoprotein component (Wrobel JK.; 2015). Such adhesion abrogation seems important in relation to arsenic. And potentially selenoglycoproteins in Taranjebin. Drinking water with arsenic relates with plasma levels of soluble cell adhesion molecules (Chen Y. and col; 2007). This is interesting from perspective of aforementioned Spanish mine workers with high arsenic and higher cancer incidence such as prostate cancer. This risk is mitigated when selenium or selenium plus nickel are elevated in nail analyses. Selenoglycoproteins are perhaps more interesting than selenoprotein alone, from perspective of glycol compounds in Taranjebin and potential cell signaling that may explaining its broad ethnomedical utility, for example in neonatal hyperbilirubinemia including thyroid immunomodulation that would help diabetes.

Selenium proteins and glycoprotein's appear to be essential in preventing liver disease and colorectal cancer. The unique elongation factor, eEFSec in RNA function producing such essential proteins indicates selenium is special when it involves synthesizing proteins via "a whole other set of rules and tools" hitherto unknown and of essential function. Selenocysteine is very unusual as it is represented in the genetic code by a codon, that signals protein synthesis to stop", helping to recognize the stop codon as actually coding for selenocysteine (DoboszBartoszek M., and col.; 2016). Furthermore, selenium can be bacterial bio-film retardant and one such study frond that selenium retarded staphylococcus by $90 \%$. Should significant Se occur in sap or honeydew exudates, particularly in mutual plant/insect benefit this would benefit both plant and insect during the plant injury and of Taranjebin production in symbiotically relations with humans and animals as postulated. (Wang Qi., and col.; 2016)

Anti-diabetes effects of sulphur selenium compound with zinc complexes have also been noted (Takayuki and col; 2017). Zinc in relation to diabetes had previously been studied from the geogenic perspective in Sweden (Haglund B. and col; 1995, 1996). This is an interesting early geogenic zinc study between childhood onset diabetes and low groundwater concentrations of zinc concluded from associate biogeochemical plant root ingress of metals in shallow waters considered a related factor to common ground water well use in rural communities. The study sourced the Swedish childhood diabetes registry (defined as onset before 15 years) data on place of residence three years before the onset of disease was correlated with biogeochemical analyses.

High zinc in these biogeochemical samples around residents to estimate proximal ground water zinc levels were found to have a significant decrease in risk $(\mathrm{OR}=0.8 ; 95 \%$ confidence interval 0.7-0.9). Interestingly also, the same $\mathrm{OR}$ was obtained when other metals, including $\mathrm{Cr}, \mathrm{V}, \mathrm{Co}, \mathrm{Zn}, \mathrm{Pb}$ and $\mathrm{Hg}$ were included as potentially confounding. Where the high zinc analyses were more tightly connected spatial to ground water wells in use the association was stronger between zinc and diabetes reduction $(\mathrm{OR}=0.6$; $95 \%$ confidence interval; $0.4-$ $0.9)$. The study concluded long term exposure to low water content zinc is associated with later development of childhood onset diabetes.

There is more to be discovered in the mechanism and possibly intermediary speciation of zinc to biota and human health on geological and geogenic vectors. Conformation of plant roots ingress to drinking well waters or alternatively food bowel from these waters in such communities in close contact with land would be an interesting study.

\section{Conclusion}

Selenium biochemistry studies indicate this essential element is an active component in Taranjebin and that its ethno medically use in immune disorders, new born hyperbilirubinemia and treatment of diabetes, as well a likely amelioration for Alzheimer's onset is supported scientifically for societies in areas of depravation. Taranjebin gum as a selenium source likely contains selenoglycoproteins, a species with various 
beneficial biological functions. We therefore recommended Taranjebin for further studies, including organic chemistry and pharmaceutical research. The geogenic speciation of zinc is highlighted in Type 1 diabetes and the Swedish study demonstrates our article theme: Primal studies need to progress before modern lifestyles overshadow geogenic factors influencing onset and evolution pathways of metabolic disease, including Alzheimer's.

\section{Materials and Methods}

Biogeochemical preparation and analytical methods were previously reported (Ziarati P. and Hochwimmer B.; 2018).

Anthropological Chemical Pollution: Heavy metals toxicity, currently available therapies and the role in Medical Geology Issues

Environmental exposure to heavy metals can result in neuropathology damage and cognitive impairment (Yang YW., and col; 2018). Heavy metals are extensively used in agriculture and industrial applications such as production of pesticides, batteries, alloys, and textile dyes, tanning, froth flotation metallurgy and chemical industries. Prolonged, intensive or excessive exposure can induce related systemic disorders (Lentini P., and col; 2017). Liver and kidney are a target organ in heavy metal toxicity for its capacity to filter, reabsorb and concentrate divalent ions. The extent and the expression of renal damage depends on the species of metals, the dose, and the time of exposure.

Yang YW and colleagues explored the association of Alzheimer's disease (AD) risk with the internal dose of heavy metals by constructing a hospital-based case-control study and using propensity-score-matching methods, where, blood levels with cadmium, lead, mercury, selenium, and urinary arsenic profile were measured. Logistic regression models and 95\% confidence intervals were applied to estimate AD risk (Yang YW., and col; 2018).

Some heavy metals in plasma exist in an ionized form essential for metabolic pathways. In additional doses heavy metals become damaging, they induce oxidative stress by generating free radicals and reducing antioxidant levels (Lentini P.; 2017). Heavy metals also alter the confirmation of protein and DNA and inhibit their function. Chelation therapy is commonly used to treat metals toxicity.

Each metal has a different reactivity with a ligand, so a specific chelation agent is required for each metal. Combination therapy with a chelating agent and an antioxidant led to improved outcome (Kim JJ., and col; 2019). Heavy metal harming is a common health problem because of mining, smelting, metallurgy, industrial, agricultural chemicals and sewage waste.

PVM under Medical Geology application can be a spatial model in analogy to finding solutions how to strip anthropogenic heavy metals in treatment with proper chelating agents and the amelioration of body heavy metal pollution with essential elements of selenium and zinc along with competitive metal (loid) species. Such beneficial and pollution metal (loids) enter the geogenic environment simultaneously, variably partitioned (Picture 2 caption). Reconciling their collective competing outcomes on Alzheimer's risks first requires geospatial studies to assess cause and effects within different environmental ratios.

PVM is the first geospatial methodology workflow steps towards unraveling such confounding factors for Alzheimer's, but must be initiate in primal society closely bound to their land, water and produce. To predict health risks with PVM targeting of Taranjebin selenium requires some understanding of geological evolution and mineralizing processes, entailing amongst others, tectonics and structural preparation. Such geology is therefore considered in some detail within the discussion section, sufficiently to explain the prediction processes of finding essential organic selenium targets in zones of depravation within in central Asia.

\begin{tabular}{|c|c|c|c|c|}
\hline $\begin{array}{l}\text { Regional } \\
\text { Zone, } \\
\text { (Market } \\
\text { Centre) }\end{array}$ & $\begin{array}{l}\text { Bulk } \\
\text { Sample } \\
\text { (Total } \\
\text { n=90) }\end{array}$ & $\begin{array}{l}\text { Selenium } \\
\mathrm{mg} / 100 \mathrm{~g}\end{array}$ & $\begin{array}{l}\mathrm{Se} \\
\mathrm{mg} / 100 \mathrm{~g} \\
\text { Zone } \\
\text { Average }\end{array}$ & $\begin{array}{l}\text { Hypothesized } \\
\text { Magmatic } \\
\text { Arc Source } \\
\text { Zones }\end{array}$ \\
\hline \multirow{5}{*}{$\begin{array}{l}\text { Zone } 1 \\
\text { PVM } \\
\text { Yazd }\end{array}$} & $\mathrm{T} 1$ & 485.54 & (Ti-T5) & \multirow{5}{*}{$\begin{array}{l}\text { Central SE } \\
\text { Zagros Zones: } \\
\text { Urumieh-Dokhtar } \\
\text { and Kerman } \\
\text { Magmatic Zones }\end{array}$} \\
\hline & $\mathrm{T} 2$ & 482.15 & 486.9 & \\
\hline & $\mathrm{T} 3$ & 491.56 & STD & \\
\hline & T4 & 488.34 & 3.5 & \\
\hline & $\mathrm{T} 5$ & 486.72 & & \\
\hline \multirow{5}{*}{$\begin{array}{l}\text { Zone } 2 \\
\text { PVM } \\
\text { (South } \\
\text { Khorasan) }\end{array}$} & T6 & 490.11 & (T6-T10) & \multirow{5}{*}{$\begin{array}{l}\text { Central Far East } \\
\text { Lut Zones: } \\
\text { Western } \\
\text { Pakistan Chagi: } \\
\text { Makran } \\
\text { Magmatic arc } \\
\text { Iranian NW } \\
\text { sinistral } \\
\text { extensions as: } \\
\text { South Khorasan } \\
\text { Magmatic Zones }\end{array}$} \\
\hline & $\mathrm{T} 7$ & 489.19 & 490.2 & \\
\hline & T8 & 493.2 & STD & \\
\hline & T9 & 491.02 & 2.1 & \\
\hline & $\mathrm{T} 10$ & 487.56 & & \\
\hline \multirow{4}{*}{$\begin{array}{l}\text { Zone } 3 \\
\text { PVM } \\
\text { (Khorasan- } \\
\text { e-Razavi) }\end{array}$} & T11 & 487.64 & (T11-T14) & \multirow{4}{*}{$\begin{array}{l}\text { North East } \\
\text { Alborz } \\
\text { Alborz Magmatic } \\
\text { Arc and } \\
\text { Khorasan- } \\
\text { e-Razavi arc } \\
\text { extensions }\end{array}$} \\
\hline & $\mathrm{T} 12$ & 502.76 & 500.9 & \\
\hline & $\mathrm{T} 13$ & 500.07 & STD & \\
\hline & T14 & 513.27 & 10.5 & \\
\hline
\end{tabular}

Table 1: East (T1-5), Central East (T6-T10) and Northeast (T11-14) Taranjebin Manna sample selenium AA analytical results assigned to corresponding PVM. Averages and standard deviations from three main City market bulked samples and hypothesis source magmatic arcs of eastern Iran. 
Results and Discussion

\section{Taranjebin Selenium in orogenic PVM context}

Figure 1 shows the main Taranjebin Manna gum source market regions in relation to regional magnetic mapping and associated major structures as fault sets and their intersections within proximal: Yazd; South Khorasan, and Korasane-eRazavi provinces, herein defined as selenium PVM adopting these place names as their labels. They are associated with the following magmatic arcs respectively, anticlockwise about the CEIM plate:

1. Central SE Zagros Zone PVM; the Urumieh-Dokhtar and Kerman Magmatic arcs (UDMA);

2. Central Far East Lut Zones PVM; Western Pakistan Chagi magmatic arcs and their western Iranian extensions as the "South Khorasan Magmatic Zones"and Makran magmatic arc;

3. North East Alborz Zone PVM: Alborz-Binalud magmatic arcs: regional Khorasan-e-Razavi magmatic arcs.

Note the increasing average Taranjebin selenium content bulked from 14 samples (Table 1) anticlockwise from south east Yazd PVM province (487 mg Se /100g), east South Khorasan PVM province (490 mg Se $/ 100 \mathrm{~g}$ ) and north east Khorasan PVM province (501mg Se $/ 100 \mathrm{~g}$ ).

Magmatic arcs, considered responsible for these mineralizations, focus about the CEIM perimeter and in relation to subduction. Taranjebin markets are proximal to nodal intersecting faults, shears, associated fractures, fractal in nature to fine scale (not shown for simplicity), evident from Figure 1, along with magnetic lineation's defining PVM, in association with volcanic and igneous selenium mineral source rocks (Figure 2), (Ziarati P. and Hochwimmer B., 2018). The later report also details biogeochemical analytical methods and reviews Taranjebin geogenic selenium with physical soil cover analyses, determined to remobilize deep selenium bioavailability to the Alhagi genus. Such deep conditions are otherwise reductive and selenium immobile.

\section{Orogenic Metallogeny in Relation to Taranjebin Spatial Selenium Biogeochemistry}

The main fractures show a marked triangular polygonal arrangement about the CEIM, a high order plate wide clustered 'PVM' reflecting the wider central Iranian 'LUT' block hosting the Yazd-Tabas-Lut basins and Sutures between former terrains (Figure 2). Nevertheless, regions of desert deprivation occur between these clusters and beyond to which Taranjebin is traded.

Southern Eurasian margin microplate geology and tectonic evolution ascribed to the Cimmerian Orogeny (CO), stretched from Turkey to Thailand. Of structural importance in terms of preconditioning PVM for both Taranjebin selenium mineralization, as well product 'quality', is the closure of the Palaeotethys Ocean about the micro continents marked by their Sutures. These deep structures penetrate to mantle, the ultimate mineralizing source, as subduction continues, providing fluid pathways to it. Such structural preconditioning are focal zones for geological mobile events that evolving toward mineralization in time and space.

Most of the colliding microplates had their origins as detachments from north Gondwana Africa in the Early Permian Neotethys Ocean (Sengo R and col; 1979, Stocklin J.; 1974, Berberian M. and King G.; 1981).

Gondwana NW Australia likely contributed to the Iranian micro continents. Perhaps pertinent for Medical Geology in Iran, very widespread heavy metal contaminated oyster occurs along the Pilbara-Gascoigne coastline of NW Australia, sourced from its ferruginous sediments (Australian Venture Consultants; 2017).

Interestingly, existing country borders roughly conform with the ancient micro plate amalgamation lines, indicating how closely geology is linked with human history. This has physiographic-geogenic mobility implications for selenium and community Medical Geology. Convergence tectonics initially squeezed up metamorphosed 'ultra-basic' upper mantle mixed with basaltic oceanic crust and sediments (called ophiolite) between, imparting enriched chromium and other heavy metals, such as nickel into the environment evidenced by replete Podiform chromite deposits (Picture 3).

Laterally compressive tectonics about the internal blocks and micro plates have induced microplate and block rotation, controlling repetitive fracturing patterns. Post compression, mineralization is normally tensional controlled on relaxation of subduction force, with resulting reverse rotation, in this case dextral, with open space in crustal dimensions to form channels for magmatic conduits. Maximum resistance to this was the Eurasian sialic plate relative to ductile CEIM, Afghanistan and Pakistan plates, yielding more brittle penetrative fracturing, and this would have focused on major Sutures and its geological and structural splays. Perhaps not incidentally therefore, Eurasia contributed to high biogeochemical selenium within Zone 3 PVM (Table 1), in addition to other factors (following).

Yazd province PVM 1 vortex with lowest bulk Taranjebin selenium $(487 \mathrm{mg} / 100 \mathrm{~g})$ is closest to the Urumieh-Dokhtar and Kerman Magmatic arcs (UDMA), part of the for-arc environment. In analogy, this corresponds palaeogeographically to the Andes or Rockies in relation to subduction Pacific Ocean plates under Americas, though of smaller scale for the Cimmerian orogenesis. Here evolving accretionary continental CEIM crust is likely thinnest, hosting porphyry copper-gold deposits, typical of forearc. More inboard intra orogenic basin extensional environments, it also hosting stratified Zinc-leadsilver barium deposits such as the important Mehdi Abad zincsilver-lead-barium mine (see Introduction and Picture 2). 
North-eastward, the next highest bulk Taranjebin selenium content occurs within south Khorasan Taranjebin Zone 2 PVM, having 490mg Se/100 g. This medium grade Zone 2 PVM selenium is also medium distal to the UDMA and therefore likely of medium crust thickness. It is juxtaposed with a resistive embayment penetrating the Helmand Block of Afghanistan. This embayment provides a wrapped structural axis preconditioning with Pakistan and Afghanistan tri junction. On collision the axis emanated of en-echelon fracturing and mineralization. The fractures are repetitively stacked fractal sigmoid en-echelon shaped faults with sinistral sigmoid inflexions clearly indicating anticlockwise rotation of the 'LUT' block of basins. This stems back to Mesozoic Trans compression, Eurasia moving west relative to sub ducting earlier Tethys Arabian ocean plate sub ducting north east as part of the Tethys Cimmerian Orogenesis (see below). YazdTabas-Lut basins comprise the Central East Iran Microplate (CEIM). Its accretion to Eurasia with lateral colliding Pakistan and Afghanistan blocks, anticlockwise rotating forces, the microplates, 'rolling' in synergy as it were. If one visualize this as a train of touching marbles rolling together it is easier to see the contacts between the blocks oppose each other, including the basin blocks and sub blocks in finer scales within each microplate. These antagonistic forces open spaces for mineralization. Interestingly, anticlockwise is also the direction of increasing Taranjebin selenium content (Table 1).

Mineral in these fracture systems is sourced from the Western Pakistan Chagi magmatic arcs and their western Iranian extensions herein the "South Khorasan Magmatic Zones (Table 1). Hydrothermal fluid from Mid-Cenozoic subduction yielding fertile calc-alkaline magmatism and volcanism. The Chagi magmatic arcs however stretch back in time inland, compounded, to at least Cretaceous as forearc environments. This conforms physiographically both sides of the border to the elevated East Iranian Range, also hosting ophiolite that separates the Central Afghanistan Microplate. South east this mobile zone hosts giant Copper-Gold porphyries of the Western Pakistan Chagi calc-alkaline volcanic arc. This prospectivity continuing into east Iran conferring the South Khorasan Taranjebin selenium supply. Consequently, additional Taranjebin PVM will likely occur in local basins within and surrounding western Pakistan Chagi volcanic arcs.

The highest bulk Taranjebin selenium of 500mg Se/100 mg in Zone 3 PVM corresponds to the furthest distance from the UDMA Zagros mobile belt and therefore likely thickest crust above this former Cenozoic Tethyan oceanic crustal slab subduction. The inboard Suture along the present-day Alborz chain in northern Iran one suggests is the focal weakness for late extension tectonics rift development. This yielded Mid Cenozoic mineralization relative to UDMA forearc subduction outboard of the Central SE Zagros Zone 1 PVM (Figure 2). Zone 3 PVM therefore comprises a backarc environment, yielding the highest Taranjebin selenium content. Physiography of the central Alborz mountains continues eastward as the Binalud mountains and Kop-Dagh mountains northwards proximal to Zone 3 PVM. Cimmerian Orogeny deformation units occur marking the Suture Zone between the CEIM and Eurasian plate, incorporating the postulated former Cenozoic Rift environment developed about the Suture between these mountain series.

\section{Zone 3 PVM Backarc Rifting and Metallogenesis}

Deformation of the former rift would have been completed with Eocene volcanism stitching the Suture focused Rift and splay structures. The Caspian Sea is a likely corollary of extension tectonics in this crustal backarc region. Indeed, further back in time it is a moot point if this was not superimposed, or structurally preconditioned on former Devonian Sutures marking a Palaeotethys rift, evidenced by Devonian alkaline basic magmatism in the eastern Alborz north of Shahrood (Ghsemi H., and Deyhimi M.; 2015).

Mesozoic, as well Cenozoic volcanism exists in the AlborzBinalud Magmatic arcs region, since a Mesozoic forearc developed on the Eurasian segment, later stitched with the Eocene mineralizing calc-alkaline to somewhat alkalic volcanism, a contributor to Zone 3 PVM selenium fertility in the Khorasan-e-Razavi district. The Suture between the CEIM and Eurasia structurally preconditioned the intrusive conduits.

Having brought the micro continents into juxtaposition, the sub ducting Tethys ocean plate, and Mesozoic forearc (at that time), would have stepped back, outboard of the UDMA, entirely contributing to Zone 1 PVM selenium in Yazd district. Here orogenic mountain building (Zagros) had reciprocal down warping in the backarc Alborz-Binalud environments, creating the rift and flexing the Suture weakness and developing backarc. Compared to the Laramide backarc rift (also hosting Fabaceae selenium flora) with shallow angle subduction location very far inland, subduction is steeper, more proximal to forearc. The ensuing extension would have released mineralizing fluids held in abeyance above mantle during compression. Magmatic suites in these environments are more hydrous and silicic due to the thicker more siliceous evolved nature of the crust.

This yields somewhat more alkalic than calc-alkaline magmatism, emanating magmatic mineralogical differences reflected in different metal deposit styles to that of forearcs, impacting Medical Geology.

The east Australian Lachlan Orogen Gilmore Suture backarc extension Rift zones to the steeper Palaeo-Pacific Ocean plate subduction is a better analogy. Typically, such rifts have more molybdenum, selenium and tellurium transition metals which in part take place of sulphur, having similar chemical properties. In forearc, sulphide species such as pyrite and pyrrhotite, (arsenopyrite is not high acid generating) which may reach $10-20 \%$ in porphyry $\mathrm{Cu}-\mathrm{Au}$ deposits. Metallogeny of back arcs systems are more commonly of low acid forming sulphide styles, such as molybdenite deposits and BMAu styles with pyrites commonly less around $2 \%$, generating less polluting AMD and ARD with more alkaline to neutral run off waters. 
Taranjebin quality may also be superior in terms of potentially less polluting heavy metal content, attributed backarc mineralization styles including BMAu styles. However, this is yet to be tested. Tectonic position suggests more evolved, brittle sialic crust with pertinent deep fracturing mineralization in conjunction with that of welded Eurasia. Gilmore Suture Rift associated porphyries with less than around 1 to $2 \%$ average pyrite include the hybrid climax Mo porphyry style, such as Mt Unicorn (Mo-Cu-Ag-Te). Molybdenum, tellurium and selenium are typical of these Metallogene. This backarc metallogeny was the lead authors first description of the PVM concept, subsequently used in exploration (Hochwimmer B.; 2004; Hochwimmer B.; 2012 a,b, Hochwimmer B. and Turnbull D., 2012).

On this analysis additional mineralization might is expected further in inboard of the Alborz-Binalud back arc- rifts regions, perhaps stronger extending into Turkmenistan, Uzbekistan and Tajikistan collated Suture focused on Rift splay intersects in analogy to the Mt Unicorn Mo-Cu-Ag-Te porphyry (Hochwimmer B.; 2012) and Laramide Orogeny rift deposits. Additionally, on this analysis, concealed MBAu types are suspected. They are deeply emplaced palaeogeographically, with passive fluid, they can be expected to be of giant size PVM zones.

Episodically cyclical trans compression and extension leading to 'pulsed' mineralization increases metal deposit grade with PVM vortex fracturing and disseminations, all factors likely contributors to the highest Taranjebin selenium in the AlborzBinalud Zone 3 PVM and likely market value. Nevertheless, whilst less polluting AMD-ARD is expected from lower acid producing species, more neutral to alkaline runoff waters can still dissolve significant dangerous transition metal (loids). This includes Cr6 + from ophiolites and arsenic from porphyries and gold stockwork's. These environments, typical of MBAu styles worldwide typically host rare manganese minerals such as kutnohorite that can be adsorptive of heavy metals such as chromium, cobalt and cadmium, ferrimolybdite and rare transition-base metal species with silver and gold compounds. We previously hinted of their presence with the character of gold mineralization in the central Alborz (Ziarati P. and Hochwimmer B.; 2018).

In conclusion: systematic anticlockwise increase in Taranjebin selenium about the CEIM perimeter is not incidental. The medical ethno-efficacy and 'quality', reflected in Taranjebin value, hinges on geodynamics of the orogenic process and tectonic position of resulting metallogene. PVM selenium and zinc vortices of these mineralization's, often 'fractal' scaled in time and space are important medically for diabetes. Concomitant metal(loid) pollution likely impacts this Medical Geology simultaneously with biological amelioration factors of essential selenium and zinc that need to be reconciled with geogenic focused epidemiological studies. Mineral deposits may be point sources, within greater environs of camp to regional host PVM, in some cases clustered on crustal scales hosting mineral deposits one considers point sources within them. This is significant as the point sources themselves may be of giant proportions, yet significantly smaller than their disseminated encapsulating PVM, albeit of lower grade. PVM is the sum of these parts with combined geogenic impacts to environment affecting food bowl soil, water and air quality and health. Legacy mine deposit alone exceeds 10,000 worldwide that are significantly un-remediated and polluting. Most PVM do not contain significant mines and therefore their impacts go largely unnoticed and since most communities never undergo epidemiological studies let alone ones that consider the geogenic environment.

\section{Geological Pvm Prospecting For Botanical Selenium Hyper-Accumulation}

Further inbound from UDMA crust deepens in the Eurasian block. As mentioned, one can expect additional backarc style mineral deposits deeper into Eurasian, within parts of Turkmenistan-Uzbekistan Tajikistan, particularly on structural fault splay intersects, proximal with Mesozoic Alborz forearc style associations of the earlier Cimmerian Orogeny. Save for climate, various selenium manna from Fabaceae genera analyses will be one way to prospect these northern sources with PVM analysis for Medical Geology impacts.

The case for a major selenium Taranjebin PVM discovery in the Western Pakistan Chagi calc alkaline volcanic arc has already been mentioned, on 'micro plate' scale. We shall now explore how this compares to smaller- 'in fractal' scales PVM analysis to find additional 'targets' illustrating PVM as a Medical Geology prospecting tool.

Compare sigmoid en-echelon fractures of east Lut block basin with central Tabas Basin where similar style yet smaller fractures reflect the smaller Tabas basins (Figures 1 and 2). Between it and the CEIM protrusion into the Helmand Afghan block, this divides the Lut block into two smaller triangulations, a fractal replication as such. The Tabas basin sigmoid fracture sets are a potential Taranjebin PVM, a smaller analogy to the larger Western Pakistan Chagi calc-Lut block sets. However volcanic and deep igneous units, including ophiolite in the adjoining Yazd and Lut basin CEIM perimeter are more prolific, based on magnetics (Figure 1), though small units will occur just not 'show up'. Southwards the Tabas basin block sigmoid fracture partners penetrate the Lut block and adjoining geological boundary fracture and (with Arabian plate influence) of the Urumieh-Dokhtar and Kerman Magmatic $\operatorname{arcs}$ (UDMA).

Potentially therefore there is a high fractal order Taranjebin PVM on the southern triangular vertex of the east Iran micro continent, a patchwork, likely fractal to the encapsulating regional PVM. Similar technique can be employed internally within PVM domains exploring ever smaller zones which likely have similar fractal nature. If replete a major PVM may be ascribed aerially clustered with mineral foci. Gridded Taranjebin selenium biogeochemical sampling and analysis is now required to discriminate these fine and course 'fractal' 
features and local essential element 'hotspots', to test these "exploration" targets.

Alteration of ophiolite in the Mesozoic to Cenozoic for selenium is also possible, or remobilized especially through subsequent volcanic hydrothermal activity. The relative contributions of volcanic to ophiolite and sediment ingress are unknown, though important to local botanic prospecting as would accompany metal (loid) in Taranjebin. Chromium from ophiolite is not all insoluble spinel in form as commonly held (Tashakor and Hochwimmer B.; 2016). Especially during protracted weathering in basins over geological time, labile chromium may occur, including more toxic $\mathrm{Cr}+6$ species labile in alkaline conditions, impacting health and possibly manna quality. Most of the geologically 'mobile' zones hosting PVM are elevated topographically with higher magnetics, replete faults and structures bounding igneous, ophiolite and volcanic units stitching marine and terrestrial sedimentarymetamorphic basin units from the Tethyan Cimmerian orogeny. Nearby, lower elevated smaller surrounding basins, have lower magnetic amplitude (blue color in Figure 1). These host Taranjebin market habitable centers. Here faults are under shallower recent sedimentary cover hosting ground waters. Major deeper central CEIM basins (Yazd-Tabas-Lut basins) have intermediate to high magnetics, separated by Trans current N-S faults normal to subduction, focused on crustal terrain fragments about which the aforementioned sigmoid fracture inflexions orientate. On intersects these are PVM targets. Mineral ground waters with selenium and other minerals would have emanated from these topographically high volcanic, deeper igneous and ophiolite unit PVM and infiltrated the small proximal basins, some on to the deeper desert marginal basins.

\section{Future Questions: Genetic Anthropology and Metabolic Disease}

Conflict between Eurasian nomadic herders and agrarian settlements has shaped Eurasian history beginning some 15-10 thousand years ago, along with agrarian practices and trade. It raises interesting questions on genetics verses behavioral adaptations, including geogenic factors on metabolic and other disorders in today's populations of central Asia and Eurasia generally. Remnants of nomadic tribes persist to this day. Transposon and other DNA elements may reveal traces of "land adaptations" between agrarian and nomadic peoples along with similar trend for cultivated wild millet and other ancient grains, parallel with essential element availability and manna biogeochemistry within these wide areas of depravation. Nomadic peoples can source and average the geogenic environment, much as modern societies emancipate from local food bowl to some degree, compared to ancient agrarians. To this day some agrarian societies are intimately connected geogenically with their land. Nomads travel to known sources of trade, as do agrarians when in need. Former Persia here was part of the fabled silk trade. Taranjebin and other manna would have traded into areas of selenium and other shortages along the desert routes.

Compared to nomads the first agrarians were of very small stature. What genetic apparatus and or cultural behaviors would have combated ensuing metabolic diseases from small birth body weight and epigenetic damage? Is such epigenetic damage cumulative? If so what adaptations are present if any? Do these genetic differences persist today and if so how do these population fair with metabolic disease in different geogenic environs and on immigration to cities of modern life? How does this compare with the high diabetes rates of South Asians and some Indian societies? Such epidemiological studies should be matched with spatial geochemistry, hydrogeochemistry controls of the geological and geogenic environment in relation to PVM analysis with gridded manna species biogeochemistry.

Parallel works on the pharmacology and organic chemistry of manna species and their selenoglycoproteins is also recommended along with manna quality in terms of pollutant metals.Such multidisciplinary study likely provides the last opportunity to study diabetes in these primal setting to answer pressing questions; what matching selenium if any and other trace element deficiencies or excess occur in such inhabitants? How do these ameliorate or exacerbate disease outcomes? These studies and more as recommended require multidisciplinary teams and significant funding.

\section{Conclusions \& Recommendations}

Essential selenium and zinc deficiencies biochemistry and physiology is reviewed to impact diabetes, neurobiology and Alzheimer's significantly whilst metal pollution may impact early Alzheimer's progression. Reconciling beneficial and deleterious metalloid factors, first requires geospatial studies within the natural physicochemical environment. Polygonal Vortex Mineralization model (PVM) analysis is the first step that may help benefit this research, to help unravel confounding biological and geogenic factors in Alzheimer's.

This supportive Taranjebin selenium biogeochemical and geogenic study is supportive. It highlights the need to concentrate further studies combining epidemiology with such geospatial geogenic in primal cultures tightly linked with land. Traded since antiquity and valued to this day, Taranjebin is harvested from Fabaceae Alhagi genus species exudates we show hyper accumulated in selenium within desert regions of deprivation. Taranjebin selenoglycoproteins are thought to be the active component used to treating immune disorders, new born hyperbilirubinemia and diabetes, combating low birth weight. Geogenic importance of zinc is also highlighted in Type 1 diabetes in a Swedish study. From market data, matched with geophysical, geological and structural data, a mineral exploration tool, PVM can explain the spatial distribution of biogenic selenium in time and space through geological and metallogene processes.

Whist PVM had been developed as a mineral exploration tool, it is proposed for the first time a novel use, that of using PVM as a health prospecting tool since most primal societies never undergo epidemiological studies integrating geology 
and its associated geogenic environment. In this case a PVM 'index' of potential public health risks such as diabetes diseases and Alzheimer's in societies closely bound with their land is concluded not only beneficial to those societies but also fundamental to Alzheimer's research.

Taranjebin selenium content bulked from 14 samples recorded increases, anticlockwise from south east Yazd PVM province (487 mg Se $/ 100 \mathrm{~g}$ ), east South Khorasan PVM province (490 mg Se $/ 100 \mathrm{~g}$ ) and north east Khorasan PVM province (501mg Se $/ 100 \mathrm{~g}$ ) associated with magmatic arcs about the Central Eastern Iranian Microcontinent (CEIM perimeter). We conclude this systematic increase is not incidental, but reflects transition from forearc to maturation of backarc environments, favoring geological evolution from calc-alkaline to more alkalic and fertile mineralizing intrusive arcs respectively in terms of selenium.

Thus, the geodynamics of the orogenic process in time and space controls the ethnomedical-efficacy and Taranjebin value, but also likely 'quality' in terms of potential heavy metal impurities. This has predictive utility outlining and defining further essential selenium target areas within areas of central Asian deprivation and potential pollution. Biogeochemical gridding is required to confirm these PVM-HI targets. PVM analysis describing those features may be used when qualified for geogenic ingress to biota and potential health impacts as health indices (PVM-HI). Spatual geogenic selenium and zinc studied demonstrate primal epidemiological studies are need before modern lifestyles overshadow geogenic factors that can influence onset, outcomes and disease evolution pathways in metabolic disease including Alzheimer's.

Primal geogenic data is overlooked, in western diabetes studies in particular. Epidemiological studies are therefore urgently need to focus on cultural settings tightly linked with land that integrate geological and geogenic environments. Integration with anthropological, epidemiological and genetic/epigenetic studies on metabolic disease have been recommended in PVM context. It is the author's expectation this paper will engender research into the validity and utility of the proposed concept of geologically based "Geogenic Public Health Indices" that may serve a first principals' approach to developing a predictive tool for confounding geogenic health issues, including type 3 diabetes (Alzheimer's disease) as a Medical Geology field.

Assessing geogenic metalloid bioavailability impacting health as Health Indices (HI), combined with PVM qualified as PVM-HI may aid mapping The Medical Geology Map of The Globe", a helpful multidisciplinary and multi-cultural enterprise. Multidisciplinary study for the current project likely provides the last opportunity to study diabetes in these primal settings and answer pressing questions; what matching selenium if any and other trace element deficiencies or pollution excess occur in such inhabitants?

\section{Acknowledgments}

Special thanks to my mom, Elisabeth, age 101 and my late sister Gerda for their love, wisdom, guidance and love of nature they instilled in me from the unique Australian bush to our beloved Austrian Alps

\section{References}

1. Avery JC, Hoffmann PR (2018) "Selenium, Selenoproteins, and Immunity"; Nutrients 1:10(9). pii: E1203.

2. Barbalace MC, Malaguti M, Giusti L, Lucacchini A, Hrelia S, Angeloni C (2019)"Anti-Inflammatory Activities of Marine Algae in Neurodegenerative Diseases", Int J Mol Sci. 2019

3. Berberian M and King G (1981) "Toward a paleogeography and tectonic evolution of Iran”. 1981, Canadian Journal of Earth Science 18: 210-265.

4. Calderón-Garcidueñas L, Gónzalez-Maciel A, ReynosoRobles R, Delgado-Chávez R, Mukherjee PS4, Kulesza RJ5, Torres-Jardón R6, Ávila-Ramírez J, Villarreal-Ríos R (2018) "Hallmarks of Alzheimer disease are evolving relentlessly in Metropolitan Mexico City infants, children and young adults. APOE4 carriers have higher suicide risk and higher odds of reaching NFT stage $V$ at $\leq 40$ years of age": Environ Res 164: 475-487.

5. Chen Y, Santella RM, Kibriya MG, Wang Q, Kappil M, Verret WJ, Graziano JH, Ahsan H (2007) “Association between arsenic exposure from drinking water and plasma levels of soluble cell adhesion molecules", Environ Health Perspect 115(10): 1415-1420.

6. Cruz-Rodriguez L, Hochwimmer B, Selinus O (2005) "Medical Geology in Cuba. 2005: ISBN 9697117037.

7. Dobosz-Bartoszek M, Pinkerton M, Otwinowski Z, et al. (2016) Crystal structures of the human elongation factor eEFSec suggest a non-canonical mechanism for selenocysteine incorporation. Nat Commun 7, 12941 (2016). https://doi.org/10.1038/ncomms12941Qi Wang, Thomas J. Webster.

8. Drel VR, Mashtalir N, Ilnytska O, Shin J, Li F, Lyzogubov VV, Obrosova IG (2006) "The leptin-deficient (ob/ob) mouse: a new animal model of peripheral neuropathy of type 2 diabetes and obesity", Diabetes. 2006 Dec;55(12):333543. Pillai R., Uyehara-Lock JH., Bellinger FP.,"Selenium and selenoprotein function in brain disorders", IUBMB Life 66(4): 229-239.

9. Elwej A, Grojja Y, Ghorbel I (2016) "Barium chloride induces redox status unbalance, upregulates cytokine genes expression and confers hepatotoxicity in ratsalleviation by pomegranate pee"l. Environ Sci Pollut Res 23: 7559-7571. https://doi.org/10.1007/s11356-0156023-0

10. Elwej A, Mariem Chaabane, Imen Ghorbel, Sabrine Chelly, Tahia Boudawara \& Najiba Zeghal (2017) "Effects of barium graded doses on redox status, membrane bound ATPases and histomorphological aspect of the liver in adult rats", (2017):Toxicology Mechanisms and Methods, 27(9): 677-686, DOI: 10.1080/15376516.2017.1351016

11. Elwej A, Imen Ghorbel, Mariem Chaabane, Nejla Soudani, 
Hela Mnif, Tahia Boudawara, Najiba Zeghal \& Madiha Sefi (2018) "Zinc and selenium modulate barium-induced oxidative stress, cellular injury and membrane-bound ATPase in the cerebellum of adult rats and their offspring during late pregnancy and early postnatal periods", Archives of Physiology and Biochemistry 124(3): 237246, DOI: $10.1080 / 13813455.2017 .1392579$

12. Garreau-Balandier I, Lefebvre M, Jacquard S, Caillat S, Cruz-Rodriguez L, Ishak L, Agier V, Morel F, Lachaume P, Dubessay P, Sauvaigo S, Alziari S, Vernet P (2014)" A J Trace Elem Med Biol. 2019 Jul;54:226-231in Drosophila melanogaster mitochondria by oligonucleotide microarray".FEBS Lett 588(9):1673-1679.

13. Ghasemi H, Deyhimi M (2015) Devonian alkaline basic magmatism in Eastern Alborz.

14. Haglund B, Ryckenberg K, Selinus O, Dahlquist G (1996) "Evidence of a relationship between childhood-onset type I diabetes and low groundwater concentration of zinc": Diabetes Care 19(8): 873-875.

15. Hamedi A, Farjadian S, Karami MR (2015)"'Immunomodulatory Properties of Taranjebin (Camel's Thorn) Manna and Its Isolated Carbohydrate Macromolecules" J Evid Based Complementary Altern Med 20(4): 269-274

16. Hochwimmer B. \& Associates Pty Ltd, "Geological consultants; Minerals Exploration, Mining Geology and Environmental Geology.

17. Hochwimmer B (2012) "The Unicorn Climax-Type Mo porphyry: A Urad-Henderson Analogy, 34th International geological oral presentation", 2012 Brisbane 2012

18. Hochwimmer B and Cruz-Rodriguez L (2005) "The Polygonal Vortex Mineralisation Model: a predictive tool of health indices and the proposed use of such "geologically based public health indices as a sub discipline of Medical Geology". 2005, ISBN 9697117037.

19. Hochwimmer BR (2004) "Internal reports on Dart Exploration License; Minerals and Petroleum Department of Primary Industry", Victoria, Australia, 2004. 13. 13.

20. Hochwimmer B (2012) The Unicorn Climax-type Mo Porphyry-a Urad-Henderson Analogy, Australian Institute of Geoscientist News No107 February 2012.

21. Hochwimmer B and Trunbal DA (2012) The Unicorn Climax-Type Mo porphyry: exploration in a newly discovered Australian molybdenum province. 34th International geological poster presentation, Brisbane 2012.

22. Industry report by Australian Venture Consultants Pty Ltd (2017) Edible Oyster Aquaculture in the Pilbara and Gascoyne Regions of Western Australia; a preliminary feasibility assessment. The Pilbara Development Commission and Gascoyne Development Commissions": 2017.

23. Jagoda K. Wrobel, Ronan Power, Michal Toborek (2016) Biological activity of selenium: Revisited. 2016 IUBMB Life

24. Kim JJ, Kim YS, Kumar V (2019) "Heavy metal toxicity: An update of chelating therapeutic strategies", J Trace Elem Med Biol 54: 226-231.
25. Konon A, Nadimi A, Koprianiuk M, Wysocka A, Szaniawski R, Wyglądała M, Słaby E, Beygi S, and Barski M (2016) "Gridded Aeromagnetic: Aeromagnetic surveys made by the Geophysics Institute of the University of Tehran, Figure 16 (A), in Formation of intracontinental basins in the opposite corners of the Tabasblock as coeval structures controlled by transpressional faulting, Iran Article in Geological Society of America Bulletin May 2016.

26. Kupka R, Msamanga GI, Spiegelman D, Rifai N, Hunter DJ, Fawzi WW (2005)"Selenium levels in relation to morbidity and mortality among children born to HIVinfected mothers", Eur J Clin Nutr 59(11): 1250-1258.

27. Kurokawa S and Berry MJ (2013)" Selenium. Role of the Essential Metalloid in Health" Met Ions Life Sci 13: 499-534.

28. Lambert Brown D, Hochwimmer B, Selinus O, Zayas Tamayo AM, Cruz-Rodriguez L. (2020) "A RNAPeptide fusion as a vaccine candidate against the novel Coronavirus (COVID-19)"; Journal of Diabetes and Endocrinology Research 2020 April 2nd, 2020: March https://unisciencepub.com/article-inpress-journal-ofdiabetes-and-endocrinology-research/

29. Lentini P, Zanoli L, Granata A, Signorelli SS, Castellino P, Dell'Aquila R (2017)" Kidney and heavy metals-The role of environmental exposure", Mol Med Rep 15(5): 34133419.

30. Lu J and Holmgren A (2008) "Selenoproteins" JBC Papers in Press, August 29, 2008, doi10.1074/jbc. R800045200.

31. Martire S, Mosca L, d'Erme M(2015) PARP-1 involvement in neurodegeneration: A focus on Alzheimer's and Parkinson's diseases"; Mech Ageing Dev 146-148: 53-64. doi: 10.1016/j.mad.2015.04.001.

32. McClintock B (1953)" Induction of instability at selected loci in maize". Genetics, pp 38, pp 579.

33. Mecocci P, Polidori MC (2012)" Antioxidant clinical trials in mild cognitive impairment and Alzheimer's disease"; Biochim Biophys Acta1822 (5): 631-638.

34. Nishiguchi T, Yutaka Yoshikawa, Yasui H (2017)"AntiDiabetic Effect of Organo-Chalcogen (Sulfur and Selenium) Zinc Complexes with Hydroxy-Pyrone Derivatives on". Int J Mol Sci 7;18(12). pii: E2647. doi: 10.3390/ijms18122647.

a. North of Shahrood: evidence for Paleotethys rifting. Iranian Journal of Geology (InPersian).

35. Qi Wang, Thomas J. Webster (2012) Nanostructured selenium for preventing biofilm formation on polycarbonate medical devices. Journal of Biomedical Materials Research Part A, 2012; DOI: 10.1002/ jbm.a.34262

36. Rachel HLH Rueli, Daniel J, Torres, Andrea ST, Dewing, Arlene C Kiyohara, Stephanie M Barayuga, Miyoko T Bellinger, Jane H. Uyehara-Lock, Lon R. White, Paula I. Moreira, Marla J. Berry, George Perry, Frederick P. Bellinger (2017) "Selenoprotein S Reduces Endoplasmic Reticulum Stress-Induced Phosphorylation of Tau: Potential Role in Selenate Mitigation of Tau Pathology", J Alzheimers Dis 55(2):749-762. 
37. Richards J, Wilkinson D, Ultrich T (2006) "Geology of the Sari Gunay Epithermal Gold Deposit, Northwest Iran," Economic Geology 101 (8).

38. Rueli RH1, Torres DJ1, Dewing AS1, Kiyohara AC1, Barayuga SM1, Bellinger MT1, Uyehara-Lock JH2, White LR3, Moreira PI4, Berry MJ1, Perry G5, Bellinger FP1 (2016)"Selenoprotein S Reduces Endoplasmic Reticulum Stress-Induced Phosphorylation of Tau: Potential Role in Selenate Mitigation of Tau Pathology"J Alzheimers Dis 55(2):749-762

39. Selinus O, Alloway B, Centeno JA, Finkelman RB, Fuge R, Lindh U, and Smedley P (Editors) (2005) Essentials of Medical Geology. Elsevier, Amsterdam, 820 p. Second edition 2013 by Springer

40. Sengo R MC (1979) "Mid-Mesozoic closure of PermoTriassic Tethys and its implications. Nature 279: 590-593.

41. Stoklin J (1974) "Possible ancient continental margins in Iran. In: BURK, C. A. \& DRAKE, C. L. (eds). The Geology of Continental Margins. Springer", Berlin 873887.

42. Tashakor M and Hochwimmer B (2015) "Geochemical assessment of serpentinite heavy metals and fluvial ingress in tropical settings". Goldschmidt 2015, Prague, Poster presentation: 2015.

43. Unjali P, Pradeepa R, Mary Beth Weber, KM Venkat Narayan, and V Mohan (2013) "Type 2 diabetes in South Asians: similarities and differences with white Caucasian and other populations", Annals of the New York Academy of Sciences 1281(1): 51-63.

44. Vindry C, Guillin O, Mangeot PE, Ohlmann T, Chavatte L (2019) "A Versatile Strategy to Reduce UGASelenocysteine Recoding Efficiency of the Ribosome Using Selenocysteine-tRNA [Ser]Sec Gene": Cells 8: 574.

45. Wrobel JK, Choi JJ1, Xiao R, Eum SY, Kwiatkowski S, Wolff G, Spangler L, Power RF, Toborek M (2015)"Selenoglycoproteins attenuate adhesion of tumor cells to the brain microvascular endothelium via a process involving NF- $\kappa$ B activation", J Nutr Biochem 26(2): 120129. doi: 10.1016/j.jnutbio.2014.09.013. Epub 2014 Oct 28.

46. Yang YW, Liou SH, Hsueh YM, Lyu WS, Liu CS, Liu HJ, Chung MC, Hung PH, Chung CJ (2018)" Risk of Alzheimer's disease with metal concentrations in whole blood and urine: A case-control study using propensity score matching", Toxicol Appl Pharmacol 356: 8-14. doi: 10.1016/j.taap.2018.07.015. Epub 2018 Jul 17.

47. Yu Chen, Regina M Santella, Muhammad G. Kibriya, Qiao Wang, Maya Kappil, Wendy J. Verret, Joseph H. Graziano, and Habibul Ahsan (2019) Association between Arsenic Exposure from Drinking Water and Plasma Levels of Soluble Cell Adhesion Molecules; Environmental Health Perspectives, 127:5, Online publication date: 1-May-2019.

48. Ziarati P and Hochwimmer B (2018) "The Medical Geology discovery of Taranjebin Manna as a hyper selenium accumulator: biomedical and ethno-medical efficacy hypothesis links to calc-alkaline and alkalic Tethyan magmatic arcs of Iran". Journal of Agricultural Science and Food" Research; 9:3.
Copyright: C2020 Cruz-Rodriguez L. This is an open-access article distributed under the terms of the Creative Commons Attribution License, which permits unrestricted use, distribution, and reproduction in any medium, provided the original author and source are credited. 